\title{
CONGENITAL CARDIAC MALFORMATIONS IN MONGOLISM
}

\author{
BY \\ J. M. BERG, L. CROME, AND N. E. FRANCE \\ From the Fountain Hospital and the Queen Elizabeth Hospital for Children, London \\ Received August 28, 1959
}

The first account of mongolism (Down, 1866) made no reference to cardiac malformations as a feature of the disease, though mentioning that "the circulation is feeble." Ten years later, Fraser (1876) published the first necropsy report of a case of mongolism, noting a small heart with fenestrated aortic valves in a 40-year-old woman. At that time, Mitchell (1876), in his notes on the physical and mental condition of so-called "Kalmuc idiots" whom he had seen, did not mention cardiac defects. Nor did Ireland (1877), though several pages of his book are devoted to a description of mongolism.

In fact, 28 years were to pass after Down's original description before an association between congenital cardiac anomalies and mongolism was suggested. The credit for this belongs to Garrod (1894) who, in a series of cases of cardiac combined with other malformations, included an 18-monthold child with mongolism. Two years later, Smith (1896), in recommending thyroid treatment in mongolism, advised a cautious dose "as the heart is undersized and weak in these patients." Garrod's continued interest in the association was demonstrated at two 1898 meetings of the Clinical Society of London. At one, he (Garrod, 1898) showed a single case, and at the second, described 5 others (Garrod, 1899), and expressed the belief that a special connection existed between congenital heart disease and mongolism. At the latter meeting, Gossage (1898) drew attention to an additional case and Guthrie (1898) mentioned two more in whom he had found septal defects at necropsy. Thomson also (1898), in a paper read before the Edinburgh Medico-Chirurgical Society, observed that he had found congenital heart disease in three cases of mongolism.

Sutherland (1899) reported that 5 of his 25 cases of mongolism had clinical evidence of congenital heart defects (in two confirmed at necropsy, one having a ventricular septal defect and the other a patent ductus), and Still (1899) observed that he had known congenital heart disease to be the cause of early death in mongolism. Neumann (1899), whom Cassel (1917) described as the first German author on mongolism, mentioned that 2 of his 13 cases of mongolism had congenital heart lesions. Neumann, whose interest in mongolism followed a visit to the Royal Albert Asylum in England, appears to be the only observer outside Britain to have noted the association of congenital cardiac lesions with mongolism before the present century. By then, this was established well enough for Sutherland (1900) to be able to list the frequency of congenital heart disease in mongolism as one of the features differentiating it from cretinism.

Thereafter, the association was frequently noted and discussed. A considerable diversity of findings and opinions has been expressed both as to the incidence and the nature of congenital cardiac malformations in mongolism. We therefore thought it worthwhile to review published data, and to study a comparatively large number of cases of mongolism, comparing the findings with those in an adequate group of controls.

\section{Source ANd Nature of Present Series}

The records and, where possible, the hearts of all cases of mongolism that came to necropsy at various periods at five different hospitals were examined. In order to collect as representative a 
sample as possible, two obstetric, one mental deficiency, and two pædiatric hospitals were chosen. These were Queen Charlotte's Maternity Hospital (Q.C.H.), the obstetrics department of Hammersmith Hospital (H.H.), the Fountain Hospital (F.H.), Queen Elizabeth Hospital for Children (Q.E.H.), all of London, and Birmingham Children's Hospital (B.C.H.). We thus gathered data on 141 necropsy cases, the largest series of its kind studied, covering the whole age range of childhood. An obvious gap is the almost total absence of adult patients, adequate data about whom we were unable to obtain. With the increasing number of mongols surviving into adult life, we hope that this may be remedied in the future.

The records of all other cases with congenital heart defects, who came to necropsy at 4 of the 5 hospitals over the same periods, were used as controls: in the case of the fifth, B.C.H., every third instance of congenital heart defects in "non-mongols" was thus selected. In this way, the appropriate time period was covered for B.C.H. also, and a total of 300 controls obtained.

The source and distribution of our 141 cases of mongolism, 79 of whom had congenital heart defects, and 300 controls are shown in Table I. The data derived from Q.C.H. and H.H. are combined in this table as most of the necropsies from these two sources were performed by the same pathologist. The 8 cases of mongolism from these two hospitals that came to necropsy from 1952 to 1957 were among 43 born there in the same period, during which a total of 31,256 babies were delivered. The 43 cases at F.H. that came to necropsy from 1950 to 1958 were among 165 cases of mongolism admitted in this time. Equivalent figures from Q.E.H. and B.C.H. are not available: the pathology departments of these two hospitals derive their material both from their own hospitals and from obstetric units that they each serve.

TABLE I

Source and Distribution of 141 NeCropsies of Mongols, 79 having Congenital Heart Defects (CHD), AND OF 300 OTHER CHILDREN WITH C.H.D.

\begin{tabular}{|c|c|c|c|c|c|c|}
\hline \multirow[b]{2}{*}{ Hospital } & \multirow{2}{*}{$\begin{array}{l}\text { Period } \\
\text { covered }\end{array}$} & \multirow[b]{2}{*}{ Age range } & \multicolumn{3}{|c|}{ Mongols } & \multirow{2}{*}{$\begin{array}{c}\text { Controls } \\
\text { No. of necropsy } \\
\text { cases (all with } \\
\text { C.H.D. } \dagger \text { ) }\end{array}$} \\
\hline & & & $\begin{array}{c}\text { No. of } \\
\text { necropsy cases } \dagger\end{array}$ & $\begin{array}{l}\text { No. with } \\
\text { C.H.D. } \dagger\end{array}$ & $\begin{array}{c}\text { Percentage } \\
\text { with C.H.D. }\end{array}$ & \\
\hline $\begin{array}{l}\text { Q.C.H.\& H.H. } \\
\text { Q.E.H. } \quad \text {. } \\
\text { B.C.H. } \\
\text { F.H. .. } \quad \text {.. }\end{array}$ & $\begin{array}{l}1952-57 \\
1947-58 \\
1938-56 \\
1950-58\end{array}$ & $\begin{array}{l}\text { SB*-3 mo. } \\
\text { SB-7 yr. } \\
\text { SB-10 yr. } \\
\frac{3}{4}-27 \text { yr. }\end{array}$ & $\begin{array}{l}8(3 \mathrm{M}: 5 \mathrm{~F}) \\
30(19 \mathrm{M}: 11 \mathrm{~F}) \\
60(31 \mathrm{M}: 29 \mathrm{~F}) \\
43(23 \mathrm{M}: 20 \mathrm{~F})\end{array}$ & $\begin{array}{r}4(3 \mathrm{M}: 1 \mathrm{~F}) \\
17(8 \mathrm{M}: 9 \mathrm{~F}) \\
43(21 \mathrm{M}: 22 \mathrm{~F}) \\
15(6 \mathrm{M}: 9 \mathrm{~F})\end{array}$ & $\begin{array}{l}50 \\
57 \\
72 \\
35\end{array}$ & $\begin{array}{r}55(32 \mathrm{M}: 23 \mathrm{~F}) \\
141(79 \mathrm{M}: 62 \mathrm{~F}) \\
99(60 \mathrm{M}: 39 \mathrm{~F}) \\
5(3 \mathrm{M}: 2 \mathrm{~F})\end{array}$ \\
\hline \multicolumn{3}{|c|}{ Totals } & 141 (76 M: $65 \mathrm{~F})$ & 79 (38 M: $41 \mathrm{~F})$ & 56 & $300(174 \mathrm{M}: 126 \mathrm{~F})$ \\
\hline
\end{tabular}

\section{C.H.D. $=$ Congenital heart defects. Criteria for inclusion enumerated in text.
$* \mathrm{SB}=$ Stillborn.}

Under the heading of congenital heart defects are included all cases showing abnormalities of the septa, valves, or great vessels, and congenital hypertrophy of the heart. Patency of the foramen ovale was only included if there was no valvular action that precluded a left-to-right shunt. Anatomical patency of the foramen ovale to a probe only was not regarded as pathological; nor was patency of the ductus arteriosus before three months of age.

\section{Incidence of Congenital Cardiac Anomalies in Mongolism}

Many authors have published figures on the frequency with which congenital cardiac defects are found in mongolism. These figures vary widely, between 7 and 70 per cent of cases of mongolism being reported to have congenital heart lesions (Table II), and there appear to be two main reasons for this.

(A) The Age Range of the Patients. In our series, excluding stillbirths, the absolute number of deaths and the percentage of deaths at various periods in the first three years of life were greater 
TABLE II

Reported InCidence of Cardiac Malformations in Mongolism

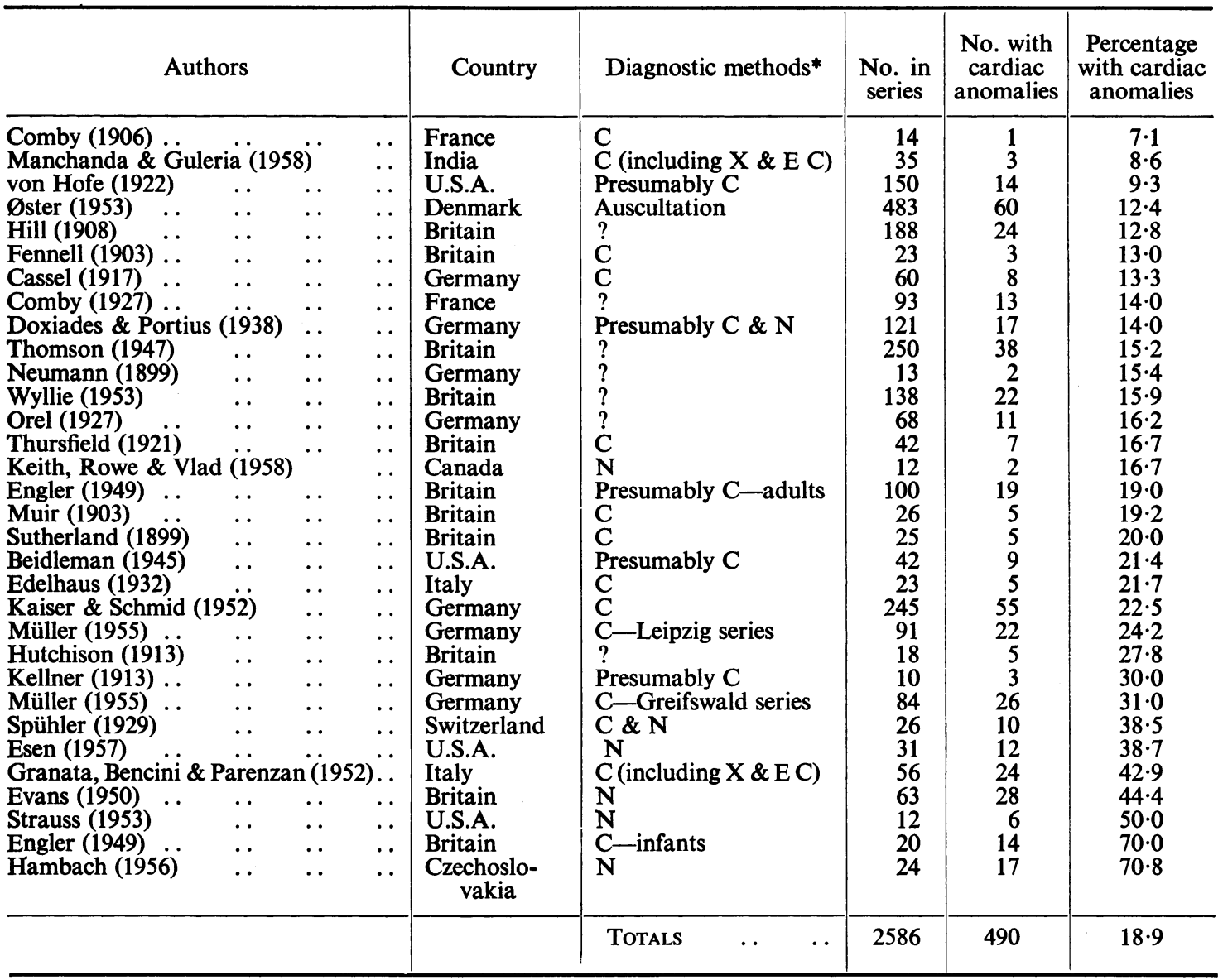

${ }^{*} \mathrm{C}=$ Clinical; $\mathrm{N}=$ Necropsy

$\mathrm{X}=\mathrm{X}$-rays; $\mathrm{E} \mathrm{C}=$ Electrocardiograms

among those with congenital heart defects than among those without such defects (Table III). In both these respects, the reverse was true among those dying from the fourth to the tenth year. The incidence of congenital cardiac anomalies in this series, in relation to duration of life, is also shown in Table III. This indicates that 66 to 72 per cent of cases of mongolism dying at various periods in the first three years of life had congenital heart lesions, compared with 19 per cent of those dying from the fourth to the tenth year.

Textbooks contain statements supporting this evidence of a higher mortality in the earlier years of life in cases of mongolism with, as opposed to those without, congenital heart anomalies (Benda, 1947; Sheldon, 1955; Ellis, 1956), and it is further borne out by reports on actual series (Thomson, 1947; Øster, 1953). In Esen's (1957) necropsy series of 31 cases of mongolism, 9 of $12(75 \%)$ with congenital heart malformations died within the first two years of life, but only 3 of $19(16 \%)$ without such anomalies died within the same period. In Evans's (1950) series of 63 necropsies, this preponderance is only present in cases dying between the 2nd and 5th month: 16 of $28(57 \%)$ with congenital cardiac lesions died in this period as opposed to 7 of $35(20 \%)$ without such lesions; but there was no proportionate difference in the death rate of his two groups during the first month and during the 6 th to 11 th months, while during the second year of life only 1 case of 8 that died had congenital 
TABLE III

Age at Death of 141 Cases of Mongolism with and without Congenital Heart Defects

\begin{tabular}{|c|c|c|c|c|c|c|}
\hline \multicolumn{3}{|c|}{ Periods taken separately } & \multicolumn{4}{|c|}{ Periods taken cumulatively } \\
\hline Deaths during & $\begin{array}{l}\text { With } \\
\text { C.H.D.* }\end{array}$ & $\begin{array}{l}\text { Without } \\
\text { C.H.D. } \dagger\end{array}$ & $\begin{array}{c}\text { Deaths during } \\
\text { (excluding stillbirths) }\end{array}$ & $\begin{array}{l}\text { Total } \\
\text { No. }\end{array}$ & $\begin{array}{l}\text { No. with } \\
\text { C.H.D. }\end{array}$ & $\begin{array}{l}\text { Percentage } \\
\text { with C.H.D. }\end{array}$ \\
\hline $\begin{array}{l}\text { Stillborn .. } \\
\text { 1st 24 hours } \\
\text { 2nd-7th day } \\
\text { 8th-31st day } \\
\text { 2nd-11th month } \\
\text { 2nd year .. } \\
\text { 3rd year .. } \\
\text { 4th-10th year } \\
\text { 15th-27th year }\end{array}$ & $\begin{array}{rr}2 & (2 \cdot 5) \\
6 & (7 \cdot 6) \\
7 & (8 \cdot 9) \\
6 & (7 \cdot 6) \\
35 & (44 \cdot 3) \\
8 & (10 \cdot 1) \\
8 & (10 \cdot 1) \\
5 & (6 \cdot 3) \\
2 & (2 \cdot 5)\end{array}$ & $\begin{array}{rr}2 & (3 \cdot 2) \\
3 & (4 \cdot 8) \\
2 & (3 \cdot 2) \\
4 & (6 \cdot 5) \\
16 & (25 \cdot 8) \\
6 & (9 \cdot 7) \\
5 & (8 \cdot 1) \\
22 & (35 \cdot 5) \\
2 & (3 \cdot 2)\end{array}$ & $\begin{array}{l}\text { 1st day } \\
\text { 1st week (inclusive) } \\
\text { 1st month " " } \\
\text { 1st year " } \\
\text { 1st two years ", } \\
\text { 1st three years (inclusive) } \\
\text { 4th-10th year }\end{array}$ & $\begin{array}{r}9 \\
18 \\
28 \\
79 \\
93 \\
106 \\
27\end{array}$ & $\begin{array}{r}6 \\
13 \\
19 \\
54 \\
62 \\
70 \\
5\end{array}$ & $\begin{array}{l}67 \\
72 \\
68 \\
68 \\
67 \\
66 \\
19\end{array}$ \\
\hline TOTALS & $79(100)$ & $62(100)$ & & & & \\
\hline
\end{tabular}

* Percentage of total with C.H.D. (79) in brackets. † Percentage of total without C.H.D. (62) in brackets.

cardiac defects. This variability will be considered later. Here we wish to observe that the percentage incidence of congenital cardiac anomalies in mongolism is partly dependent on the age range of the patients under consideration, the evidence indicating that in general an undue proportion of those with such anomalies die early.

(B) The methods and criteria on which diagnoses of congenital cardiac anomalies are based. Of the 17 mongols at Queen Elizabeth Hospital and the 15 at Fountain Hospital in whom congenital cardiac defects were found at necropsy (Table I), $13(76 \%)$ and $10(67 \%)$ respectively were diagnosed as having such defects in life during routine clinical examinations without the aid of special investigations. Similar data are not available for the rest of our series, but published reports (Fennell, 1903; Comby, 1906; Turpin and Gorin, 1941), as well as our material, show that cardiac malformations in mongols may be found at necropsy without being suspected during life. Further, the use of diagnostic aids, like angiocardiography and cardiac catheterization, is likely to yield more accurate figures than clinical examination alone, and will thus also affect the incidence of cardiac defects noted in mongolism.

Since only a minority of mongols with congenital cardiac lesions display frank cyanosis, clubbing, cardiac failure, or other relatively obvious features of heart disease, clinical diagnosis largely depends on examination of the heart itself. This makes for diagnostic variations dependent not only on the skill and experience of the examiner but also on the criteria accepted for what constitutes an abnormal heart. Even in necropsy series criteria vary, some for instance excluding patent foramen ovale or patent ductus below a certain age, others differing in the degree of patency accepted as abnormal.

Clearly, therefore, if figures quoted for the incidence of congenital cardiac defects in mongolism are to be significant, both the age range of the patients and the diagnostic techniques and criteria used must be stated. These factors no doubt account for much of the percentage variations quoted in Table II and many authors give no information on these points. Consideration of the remaining series indicates that differences may occur even when the age range and diagnostic methods are similar. In some instances this may be due to the smallness of the series. Thus, Evans (1950) found 1 instance of cardiac malformations among 8 cases of mongolism $(12.5 \%)$ dying in the second year of life, while in our series, there were 8 such instances among 14 cases $(57 \%)$ dying in the same age range. Table IV illustrates the point further.

\section{Nature and Variety of Congenital Cardiac Malformations IN Mongolism}

Review of Published Data. The earliest reports on cardiac anomalies in mongolism were based chiefly on clinical observation, and the precise nature of the anomalies was seldom specified. 
TABLE IV

Incidence of Congenital Heart Defects in Mongols Dying in the First Month of Life

\begin{tabular}{cr|c|c|c}
\hline \multicolumn{1}{|c|}{ Series* } & $\begin{array}{c}\text { No. of } \\
\text { deaths }\end{array}$ & $\begin{array}{c}\text { No. with } \\
\text { C.H.D. }\end{array}$ & $\begin{array}{c}\text { Percentage } \\
\text { with C.H.D. }\end{array}$ \\
\hline Present . . & $\ldots$ & 28 & 19 & 68 \\
\hline Evans (1950) & $\ldots$ & 9 & 4 & 44 \\
\hline Keith et al. (1958) & 12 & 2 & 17 \\
\hline
\end{tabular}

The probability that the differences in incidence of congenital heart defects in these series is due to chance is less than 1 in 100 by the $\chi^{2}$ test.

Modern knowledge of congenital heart disease owes much to Maude Abbott, and one of her many publications dealt with the heart of a case of mongolism aged 10 months (Abbott, 1924): it showed persistent ostium primum, and she commented that in her experience the cardiac defect in mongolism was not infrequently of this type. Abbott's observation was the first of many in which either persistent ostium primum or the related anomaly, persistent ostium atrio-ventriculare (A-V) commune, were reported in cases of mongolism. She herself returned to this subject (Abbott, 1936) in the following terms.

"Combined partial defect of the lower part of the interauricular (persistent ostium primum) and upper part of the interventricular septa, constituting the so-called persistent ostium atrio-ventriculare commune, forms a well-recognized group of anomalies, in which a more or less free communication exists between all the four chambers of the heart, which functions, where the septal defect is large, as a biloculate organ. Cleavage of the anterior mitral and deformity of the tricuspid segments is a constant feature of persistent ostium primum, and, when the interventricular septum is also largely defective, a complete separation of each of these cusps into two halves occurs, the contiguous parts of which are continuous, each with the other, over the free septal border. The condition is explained as a failure of upward growth of the ventricular septum, combined with an arrest of fusion of the auriculo-ventricular endocardial cushions with the free lower border of the septum primum. A feature of extraordinary interest is the frequent combination of mongolian idiocy with this form of defect and with persistent ostium primum per se. This combination calls for explanation."

To illustrate the condition, she cited three further instances of persistent ostium A-V commune in mongolism. Case reports exemplifying this association were also contributed by Schleussing (1925, Case 5), Gunn and Dieckmann (1927), Robson (1931), Meeker (1935), Goetsch (1938), Robinson (1941), and Hambach (1953). The incidence of persistent ostium primum and persistent ostium A-V commune in reported series of cases of mongolism will be referred to below.

Keith (1909), among the first to describe persistent ostium A-V commune, did not mention whether any of the 14 cases he had seen had mongolism. Nor did Sikl (1951) refer to the incidence of mongolism in the 35 instances of persistent ostium A-V commune found amongst 228 children with congenital cardiac defects who came to necropsy in Czechoslovakia. Since persistent ostium A-V commune is one of the more severe of cardiac malformations, it is likely that those so affected would tend to die in childhood, and Keith (1909) mentioned that he had not seen the lesion in an adult.

Though relatively common in mongolism, persistent ostium $\mathrm{A}-\mathrm{V}$ commune and persistent ostium primum are by no means restricted to mongolism and many instances in subjects without mongolism have been recorded. Among these are case reports by Schleussing (1925, Case 6), Morgan and Sprenkel (1936, a mentally defective woman who survived till 60 years) and Lightner (1939), who observed that, of some 30 instances of persistent ostium A-V commune reported, about half had occurred in mongols. The view expressed by Potter (1952) is therefore somewhat startling: she wrote that this defect "is limited almost entirely to mongolian idiots and has been called the 
Mongol defect. I have never observed the defect in an otherwise normal infant. In recently reviewing over 10,000 autopsy reports on infants less than one year of age, I found it exclusively limited to infants with mongolian idiocy and it was present in almost all the infants with mongolism."

In general, published reports agree that there is a very wide scatter of cardiac lesions in mongolism, even if allowance is made for lack of precision and uniformity in the terminology employed. In a study of mongolism in Zurich, Spühler (1929) noted cardiac anomalies at necropsy in 6 casesventricular septal defect (4), cor biatrium univentricularis with patency of the ductus and foramen ovale (1), and essential hypertrophy of the heart (1). Maladie de Roger was also noted with comparative frequency in earlier French reports. A single case, diagnosed clinically, was reported by Armand-Delille (1908), and Comby (1927), without stating how the diagnoses were made, found it to be the commonest lesion in 13 cases with congenital heart disease among 93 mongols. Similar views were expressed by Silvy (1934), who reviewed 51 reported cases of mongolism with congenital heart defects, adding 4 of her own; in the total of 55 cases, 34 were stated to have had isolated maladie de Roger. This view of the frequency of the maladie de Roger was, however, often expressed about series of all types at that time when clinical diagnosis of congenital heart disease was much less accurate than it is now.

In Leech's (1935) series of 75 necropsies on children with congenital heart lesions at John Hopkins Hospital, 5 had mongolism, ventricular septal defect being the sole lesion in 2, patent ventricular and atrial septa in 1, persistent ostium A-V commune in 1 (not described by this name-Case 69), and aortic stenosis with patent foramen ovale and ductus arteriosus in 1 case. Single cases with patency of the ventricular and atrial septa were also recorded from Germany by Cassel (1917) and from Buenos Aires by Albores and Caprile (1944).

Ingalls's (1947) necropsy series of 32 cases of mongolism from the Boston Children's Hospital included 14 with ventricular septal defects and 8 with persistent ostium primum: valvular insufficiency was frequent and a persistent left superior vena cava and unspecified septal defect were present in 1 case. Turpin and Gorin (1941) described an unusual malformation in a girl of 16 months with mongolism who, in addition to persistent ostium primum, had a mitral orifice divided transversely by a fibrous band that gave attachment to somewhat deformed valves.

In a series from Chicago of 105 necropsies on children with congenital heart disease, 7 had mongolism (Gibson and Clifton, 1938): of these, 2 had persistent ostium primum, one with a ventricular septal defect as well; 1 had a ventricular septal defect alone; 2 had patent ductus arteriosus; and 2, Fallot's tetralogy. Single cases of mongolism with Fallot's tetralogy were also reported by Wolf and Levinsohn (1939), Bor and Padovcová-Ledererová (1951), Ghosh and Biswas (1955), and by Castleman and Kibbec (1957): an atypical feature of the last was the presence of a persistent common A-V canal instead of the common variety of ventricular septal defect.

Bor and Padovcová-Ledererová's material also included a mongol with persistent truncus communis and two with transposition of the great vessels. Transposition of the great vessels in a case of mongolism had earlier been reported by Doxiades and Portius (1938) and by Mannheimer (1949). Evans (1950) found no examples of transposition of the great vessels, truncus arteriosus, or coarctation of the aorta among 28 children with mongolism who died in the first five years of life with congenital heart defects. In contrast with this, Hambach (1956) was struck by the frequency of transposition of the great vessels in his material, finding this malformation 6 times, and coarctation of the aorta once, in his series of 17 necropsies on children aged up to 18 months with mongolism and congenital heart disease: persistent ostium $\mathrm{A}-\mathrm{V}$ commune was present in 5 of his cases and others had various septal defects.

A high incidence of persistent ostium A-V commune has often been noted in recent series of cases of mongolism. In Evans's (1950) necropsy series, it occurred in 4, and pulmonary stenosis in another 4: ventricular and atrial septal defects each accounted for one-third of the individual lesions and patent ductus for one-sixth. From Milan, Granata et al. (1952) reported on 56 mongols, 24 of whom had congenital heart defects: no less than 14 were stated to have persistent ostium A-V commune, 5 others had atrial septal defects, 2 had Eisenmenger's complex, and 1 each had Lutem- 
bacher's syndrome, patent ductus, and aortic stenosis. Twelve necropsy records of patients with mongolism at the Mount Sinai Hospital were found by Strauss (1953): of the 6 with congenital heart defects, all of whom died by the age of 7 months, 4 had persistent ostium A-V commune, 1 had Eisenmenger's complex, and 1 atresia of the pulmonary valve with ventricular septal defect and dextroposed aorta.

Comparable findings were those of Rowe and Uchida (1956, quoted by Keith et al. 1958). The lesions in their 31 cases were: persistent ostium A-V commune (11 cases), ventricular septal defect (11), atrial septal defect (3), patent ductus (3), atrial and ventricular septal defects (1), pulmonary stenosis (1), and isolated aberrant right subclavian artery (1 case). In the 12 necropsy reports of cases of mongolism with congenital heart lesions presented by Esen (1957) persistent ostium A-V commune occurred 7 times: 2 others had ventricular septal defects, 2 atrial septal defects, and 1 Eisenmenger's complex.

Kaiser and Schmid (1952) studied 245 persons with mongolism, of whom 55 had clinically diagnosed congenital heart disease, including 25 with necropsy reports. They considered the combination of lesions in 14 of these 25 as indicative of a "mongol cardiac syndrome" which could be present in a mild or severe form. The mild form, present in 7 cases, consisted of a combination of atrial septal defect, ventricular septal defect and patent ductus. The severe form, also present in 7 cases, consisted of persistent ostium A-V commune which could be associated with patent ductus. The remaining 11 cases of their series had various isolated lesions, including 2 cases with abnormal termination of a pulmonary vein and 1 with abnormal origin of a subclavian artery. They referred to pulmonary stenosis and transposition of the great vessels as amongst the rarer anomalies in mongolism.

Müller (1955), who also considered the question of specific cardiac lesions in mongolism, did not find this in his material. He reported the necropsy findings in 18 cases, nearly all under 6 months of age, and listed the cardiac lesions individually in each case: these do not include named examples of persistent ostium primum or persistent ostium A-V commune, although at least two, Cases 5 and 17, seem, from the description given, to be of this nature. Alone, or in combination with other lesions, ventricular septal defects were present in 7 others, patent foramen ovale in 8, patent ductus in 6, anomalies of the aortic valve in 3, and of the mitral valve in 2: pulmonary stenosis, dextroposition of the aorta, and transposition of the great vessels occurred once each.

\section{Results in Present Series}

A detailed analysis of the cardiac anomalies found in our 79 cases of mongolism and 300 other children with such anomalies, in terms of age at death and sex, is given in the appendix (see p. 344) and is summarized in Table V. All the original diagnoses and descriptions of the hearts were made by, or under the supervision of, experienced pathologists, but criteria for classification and terminology varied inevitably between the hospitals and, to some extent, within the same hospital. Thus, some cases were given only a brief diagnosis, while others were described in detail. In general, such detailed descriptions were given to cases not fitting clearly into well-recognized syndromes or anomalies. On the other hand, "blanket" diagnostic terms, such as Fallot's tetralogy or persistent ostium A-V commune, tended to conceal unmentioned, but possibly significant, differences between cases. Moreover, teminology employed by different pathologists reflected certain individual preferences. It was thus necessary to reconsider each case in order to unify nomenclature, where possible, for purposes of comparable classification. In doing this, we adopted the following rather arbitrary criteria.

When combinations of anomalies had been described by "blanket" diagnostic terms, such terms were retained. This applied particularly to persistent ostium A-V commune, Fallot's tetralogy, Eisenmenger's complex, and cor biloculare and triloculare. Where such terms had been used and additional anomalies also described, both the term and additional anomalies were listed in the appendix. Similarly, all the lesions were listed in the appendix in cases having various combinations of abnormalities, even if such combinations occurred only once. In Table V also, the "blanket" terms 
TABLE V

InCidence of Various Malformations in 79 Mongols and 300 other Children with C.H.D.

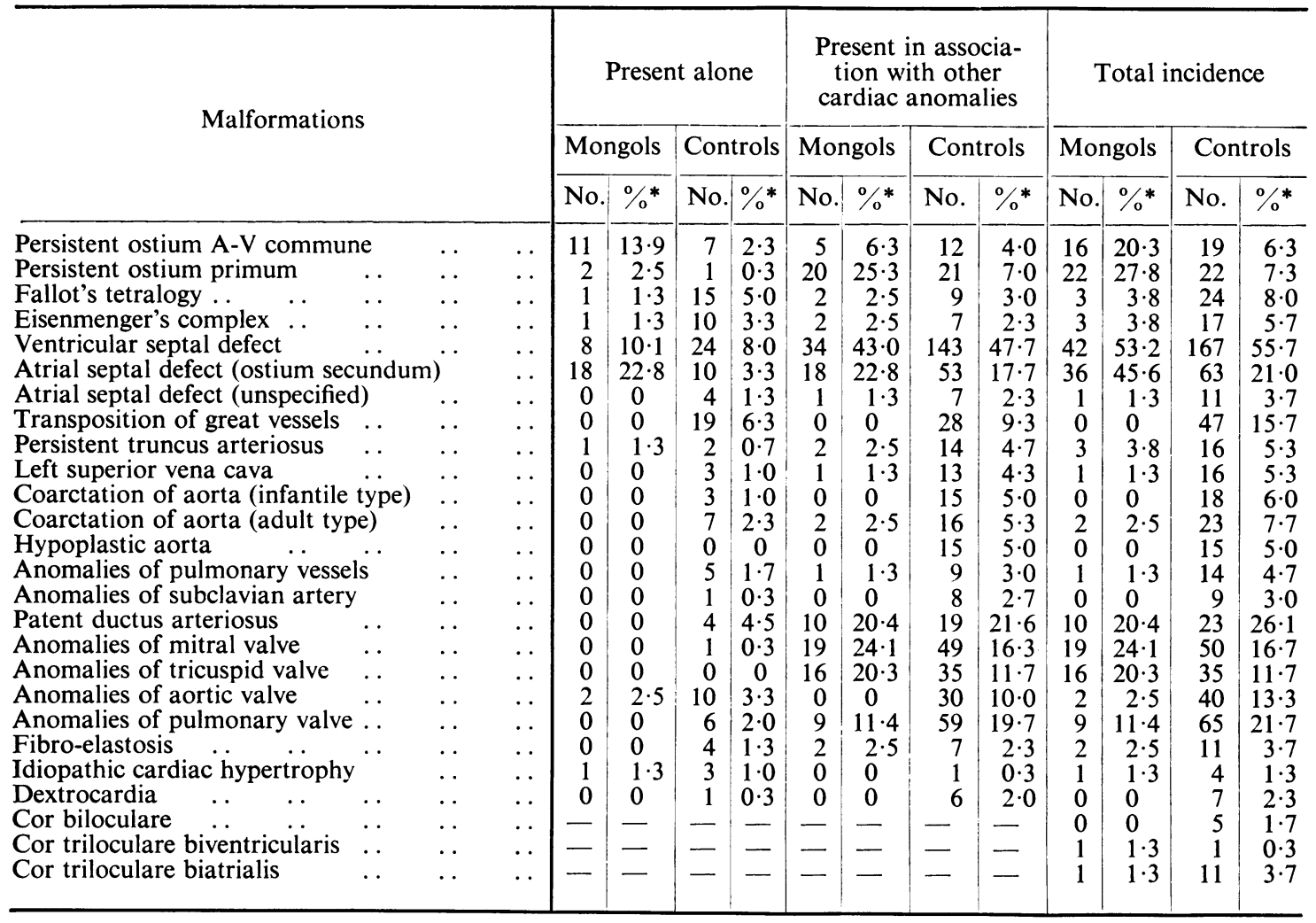

* Percentages calculated in terms of number of cases in appropriate series (i.e. 79 mongols and 300 controls), except for patent ductus arteriosus where percentages are based on number of cases aged 3 months or more at time of death (i.e. 49 mongols and 88 controls).

were retained but, in addition, the conditions they referred to were sub-divided into individual anomalies where this seemed appropriate. Thus, for example, ventricular septal defect present in association with other cardiac anomalies includes all cases of persistent ostium A-V commune, Fallot's tetralogy, Eisenmenger's complex, cor biloculare, and cor triloculare biatrialis.

Atrial septal defects were listed by us only if they were functional as well as anatomical, permitting a left-to-right shunt: size of the patency and whether single, multiple, or fenestrated were too often omitted in the original descriptions to make them criteria for further subdivision. Ventricular septal defects had sometimes been recorded as membranous and other times as muscular, but most were unspecified: while it seemed that most of the unspecified ones were membranous, we thought it inaccurate to attempt such subdivisions in our tables.

Anomalies of the valves are individually listed in the appendix, but all anomalies of each valve are totalled in Table $\mathrm{V}$, where anomalies of the mitral valve, for example, include stenosis, regurgitation, hypoplasia, and atresia of that valve. Patency of the ductus arteriosus was only recorded by us if it was still present at three months of age or later. Since few heart weights were available, we have disregarded these entirely. It is realized that some significant facts may have been omitted and that some of the listed ones are of doubtful importance. Since, however, the same criteria were used for the cases of mongolism and the controls, conclusions from comparisons of the two groups seem justifiable. 


\section{Discussion}

Our results show that the abnormal hearts of mongols display, in general, as wide a variety of malformations as those of subjects without mongolism, most cardiac defects being represented in both groups (See Appendix and Table V). It is evident that even such well-defined syndromes as persistent ostium A-V commune, Fallot's tetralogy, and Eisenmenger's complex are not necessarily strictly homogeneous and may be associated with additional anomalies. Taking account of such additional anomalies, the percentage incidence of lesions or combinations of lesions that occurred once or twice only in mongols and in controls is practically identical in the two groups: lesions or combinations of lesions occurred once only in 22 of the 79 cases of mongolism $(28 \%)$ and 89 of the 300 controls $(30 \%)$; the figures for lesions or combinations of lesions that occurred twice only are 6 of $79(8 \%)$ and 12 of $300(4 \%)$ respectively.

There is no reason to believe that, had our series of mongols and of controls been larger and equal in size, all the unusual combinations of lesions would not have been encountered in both groups. Nevertheless, quantitative differences between the two groups seem real enough, though caution is necessary in interpreting some of these. For instance, the view of such a recognized authority as Maude Abbott, who has associated persistent ostium A-V commune and persistent ostium primum specifically with mongolism, has probably influenced other workers. Hence, conditions resembling persistent ostium A-V commune and persistent ostium primum would tend to be described as such in mongols, and by some alternative designation (e.g. cor biloculare or cor triloculare) in other cases. Though on guard against this, we were not always certain of the classification and retained the original terms used by the pathologists in doubtful cases. It may well be, therefore, that the relative preponderance of these two malformations in mongols and of cor biloculare and cor triloculare biatrialis in others is partly due to this cause. Subject to these reservations, our findings confirm the comparative frequency of persistent ostium A-V commune and persistent ostium primum in mongolism that has been noted by numbers of authors. We found a 20 per cent total incidence of persistent ostium A-V commune in mongols as opposed to 6 per cent in the controls; the equivalent percentages for persistent ostium primum are 28 and 7 per cent. The latter two figures include cases of persistent ostium A-V commune, but even if these are excluded there is a preponderance of persistent ostium primum in cases of mongolism of 7.5 as opposed to 1 per cent in the controls.

Our data show a total percentage incidence of Fallot's tetralogy twice as high, and of Eisenmenger's complex one and a half times as high, in the controls as in the mongols. Differences of this order should be interpreted with caution in view of differences in age at death between our samples of mongols and of controls.

There was no substantial difference between the mongols and the controls in the percentage incidence of ventricular septal defects, either occurring alone or in combination with other cardiac anomalies. On the other hand, atrial septal defects of ostium secundum type were relatively less common in the controls. We think that most of the atrial septal defects of an unspecified nature were, in fact, defects of ostium secundum type.

Like Evans (1950) in his series, we found no examples of transposition of the great vessels in our mongols. Although such examples have been reported, the association appears to be comparatively rare, Hambach's (1956) experience of finding 6 instances of it in 17 necropsies being exceptional. We were also struck by the comparative infrequency of other vascular lesions in our cases of mongolism - coarctation of the aorta of infantile type, hypoplastic aorta, and subclavian artery anomalies were not recorded at all in this group, and persistent truncus arteriosus, left superior vena cava, coarctation of the aorta of adult type, and pulmonary vascular anomalies comparatively less frequently than in the controls. The absence of hypoplastic aorta in the mongols, as opposed to a 5 per cent incidence in the controls, is surprising and difficult to explain, in view of the tendency in mongols for all arteries, including the aorta, to be small. However, the term hypoplastic has been generally used without measurement of diameter, and we suggest that quantitative study is required before conclusions are accepted. Patent ductus arteriosus, as an isolated lesion, was not noted in 
the mongols, but there was little difference in its relative incidence in this group and the controls when associated with other cardiac anomalies.

Anomalies of the mitral and tricuspid valves were comparatively less frequently noted in the controls, and anomalies of the aortic and pulmonary valves more often. In the case of aortic valve anomalies, the total percentage incidence was five times higher in the controls. However, the anomalies were of various kinds and it may not be justified to analyse them in terms of this single heading. Fibro-elastosis was one and a half times as common in the controls. Idiopathic cardiac hypertrophy had an equal percentage incidence. Dextrocardia, absent in the mongols, had a 2 per cent incidence in the controls.

The range of cardiac anomalies in mongolism appears to be as wide as that in subjects without mongolism. In those few instances where a particular lesion was not noted in our series of 79 mongols, we found reports of its occurrence by other workers. Qualitatively, therefore, a concept of a "mongol heart" appears to be unjustified, but quantitative differences do emerge in a comparison of the malformed hearts of those with and those without mongolism. This must be coupled with the remarkably high general incidence of heart lesions in mongols, unparalleled in any other single disease save, possibly, rubellar embryopathy.

In any disease of unknown ætiology, it is important not to overlook any clues presented by a recurrent pattern of abnormalities. Mongolism abounds with such patterns, i.e. cranial and facial features, brain configuration, leucocyte picture, 'blood chemistry, level of intelligence, and so on. Cardiac malformations may possibly be more significant than some of the others since the stages of normal development of the heart are relatively better known, and it is therefore possible to time the onset of a disturbance leading to faulty cardiogenesis more accurately than with some other organs.

In a $3.9 \mathrm{~mm}$. human embryo, the A-V canal is already well-formed and partly filled by the two endocardial cushions, though these show no evidence of fusion (Mall, 1912). By the end of the fifth week of development (Keith, 1909), when the embryo is about $5 \mathrm{~mm}$. long, the central parts of these cushions, lying directly over the interventricular septum, fuse, and the line of fusion then extends outwards in both directions to become complete in a 9-mm. embryo (about 40 days). Complete closure of the ostium primum and the interventricular septum is contingent upon the preceding closure of the A-V canal by the endocardial cushions, and is complete by the 47th day of development. It is thus evident that the cause of non-closure of the A-V canal must operate before the 40th day of gestation, while that responsible for the septal abnormalities may operate either within the same time-span or a little later-up to the 47th day. The same consideration applies to the division of the truncus arteriosus into the pulmonary artery and aorta, which is only complete in a 20-mm. embryo.

In view of the confusion sometimes present regarding the timing of ætiological agents in relation to normal development, it is worth making the obvious point that the earliest time limit for the action of any teratological cause can never be inferred solely from the known landmarks of normal development. This is so because many causes may be followed by delayed rather than by immediate effects. Thus, the occurrence of a patent ductus arteriosus, a structure normally closing only after birth, does not indicate that the cause operated late in fœtal development. The upper time limit for the onset of the many other anomalies occurring in the hearts of children with mongolism and other children have not been worked out precisely, but there is no reason to believe that the cause responsible for cardiac malformations in mongolism acts earlier than in other cases. The only conclusion justified by the evidence is that the initial cause or causes responsible for heart defects in mongolism, and by inference for mongolism itself, operate predominantly before the 40th day and, in any case, not later than the 50th day of gestation.

The great and unresolved problem of whether the disease is incurred before or after conception is unaffected by these considerations. However, the recent demonstration of the anomalous number of chromosomes - 47 instead of the normal 46, in the bone-marrow cells of cases of mongolism (Ford et al., 1959; Jacobs et al., 1959) will provide, when confirmed, positive evidence of the preconceptual operation of at least some of the factors involved in the causation of mongolism. 
It would also be of great interest to compare the nature of cardiac malformations in mongolism with those produced by maternal rubella, the only certain environmental cause acting in utero. Detailed comparison is not yet possible as comparatively few records of rubellar cardiopathy have been published. Among the larger series are those of Gibson and Lewis (1952) and Stuckey (1956). Gibson and Lewis elicited, on questioning, a history of maternal rubella during pregnancy in 17 cases of congenital heart disease: 14 had patent ductus, associated with ventricular septal defect in two instances and with pulmonary stenosis and coarctation of the aorta in one each; 1 had atrial septal defect, 1 ventricular septal defect, and 1 Fallot's tetralogy. Of the 27 cases of rubellar cardiopathy reported by Stuckey, 13 had patent ductus; 4, a ventricular septal defect; 3, an atrial septal defect; 2, Fallot's tetralogy; and there was one example of each of the following, aortic stenosis, pulmonary stenosis, coarctation of the aorta, Eisenmenger's complex, and transposition of the great vessels: the diagnosis was confirmed in 7 at operation, in 6 by angio-cardiography or cardiac catheterization, and in 7 at necropsy.

Thus many different cardiac anomalies may result from maternal rubella, though patent ductus appears to be outstandingly common. Since final closure of the ductus could be prevented by causes operating later than those responsible for most other congenital cardiac anomalies, Stuckey postulated that the high incidence of patent ductus in rubellar cardiopathy, compared with its incidence among those with congenital cardiac defects in general, suggèsts a relative prevalence of genetic causes in the latter in contrast with the environmental cause (the virus) in the former. In the light of this suggestion, it is interesting that the total incidence of patent ductus in our cases of mongolism with congenital heart defects $(20 \%)$ was similar to that in the controls $(26 \%)$.

\section{Other Congenital Malformations in Mongols}

Apart from congenital heart defects and the well-known physical characteristics classically associated with mongolism, a wide range of other congenital anomalies may occur. Those found at necropsy in our series of 141 cases of mongolism are shown in Table VI. Particularly striking is the relatively high incidence of duodenal stenosis and atresia, a feature to which Bodian et al. (1952) have previously called attention.

\section{SUMMARY}

A historical note is presented on the earliest observations of the association of congenital cardiac malformations with mongolism. By the end of the 19th century this association was well-recognized.

Anything between 7 and 70 per cent of cases of mongolism are reported to have congenital heart lesions: most reports, however, gave between 12 and 44 with an average of 19 per cent. This wide range of percentages is attributed to two main reasons: (A) the age range of the patients under consideration, and (B) the methods and criteria on which diagnosis of congenital cardiac anomalies are based. Each of these factors is considered, and a plea made that both should be stated when quoting figures for the incidence of cardiac malformations in mongolism. Considerable variation in this incidence still occurs when comparing different series matched for these two factors, but sometimes the series are too small to expect good agreement.

The cardiac malformations reported in mongolism are reviewed, and those found in 79 of our own cases of mongols with congenital heart defects are compared with those in 300 controls drawn from the same sources. The variety of cardiac anomalies in the mongols was as wide as in the other children. Unusual combinations of lesions, noted once or twice only in either group, occurred with almost equal frequency in each group. On a qualitative basis, therefore, a concept of a "mongol heart" appears unjustified. However, there are some quantitative differences:

Persistent ostium primum, persistent ostium A-V commune, atrial septal defects of ostium secundum type, and anomalies of the mitral and tricuspid valves were more frequently noted in the cases of mongolism.

Fallot's tetralogy, Eisenmenger's complex, persistent truncus arteriosus, left superior vena cava, coarctation of aorta of adult type, pulmonary vascular anomalies, anomalies of the aortic and 
TABLE VI

Other Congenttal Malformations in 79 Mongols with, and 62 without, Congenital Heart Defects (C.H.D.)

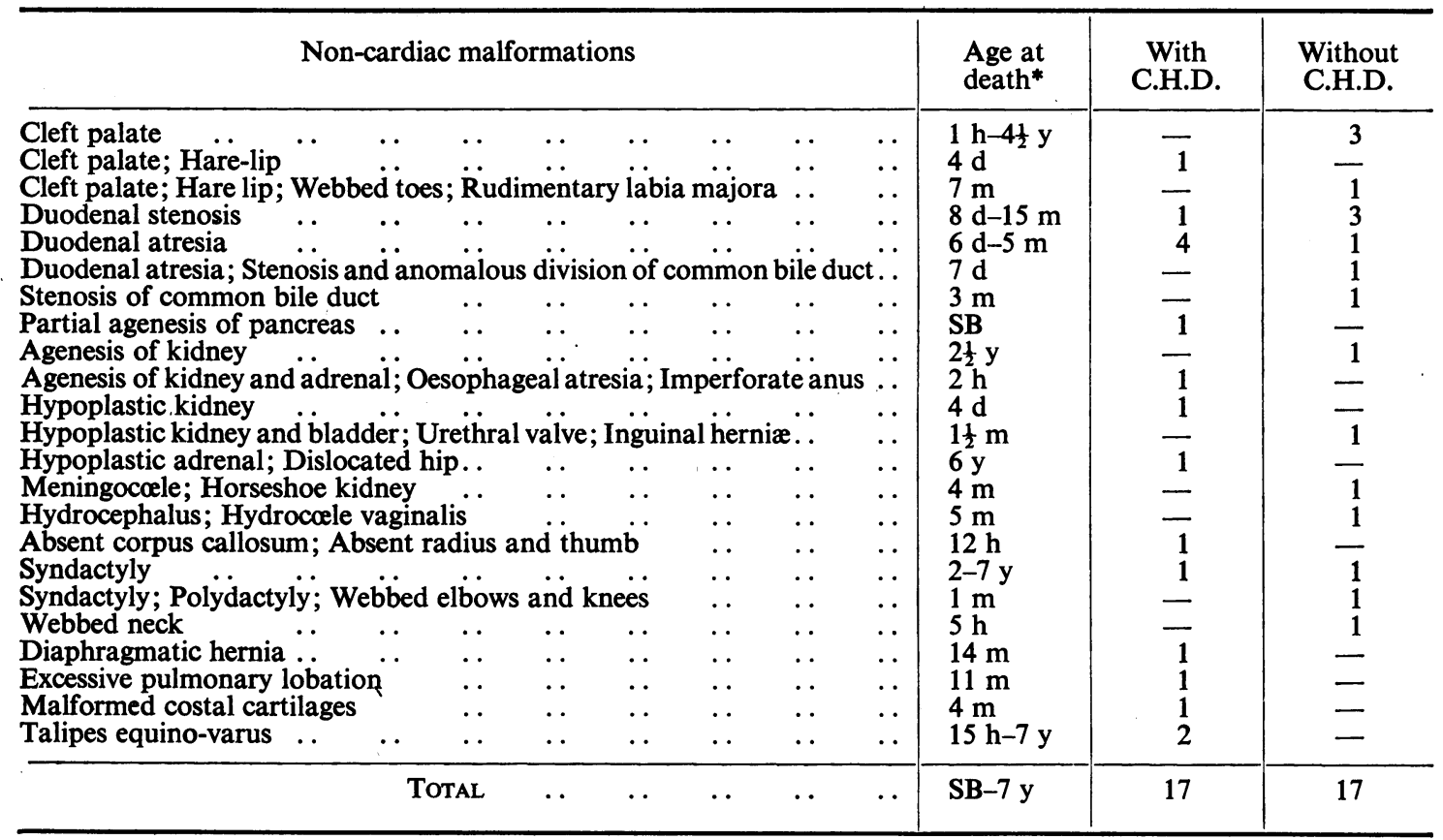

* SB=stillborn. $\mathrm{h}=$ hours. $\mathrm{d}=$ days. $\mathrm{m}=$ months. $\mathrm{y}=$ years.

pulmonary valves, and fibro-elastosis were less frequently noted in the cases of mongolism. Lesions not found in the mongols but found in the controls included transposition of the great vessels, coarctation of aorta of infantile type, subclavian artery anomalies, and dextrocardia, but examples of such lesions in mongols had been recorded by other workers.

Ventricular septal defect, patent ductus arteriosus, and idiopathic cardiac hypertrophy were noted about equally in the mongols and in controls.

Congenital non-cardiac malformations noted at necropsy in our 141 cases of mongolism are tabulated.

It is a pleasure to thank Dr. A. H. Cameron of Birmingham Children's Hospital and Dr. A. E. Claireaux of Queen Charlotte's and of Hammersmith Hospitals for access to their post-mortem records, and Dr. R. E. B. Hudson of the National Heart Hospital, for his comments on some of the specimens and his useful advice.

We are indebted also to clinicians and other members of the staff of the five hospitals surveyed for placing their records at our disposal and for their helpfulness, and to Dr. Maurice Campbell for making valuable suggestions about the arrangement of our paper.

\section{REFERENCES}

Albores, J. M., and Caprile, J. A. (1944). Arch. argent. Pediat., 15, 432.

Abbott, M. E. (1924). Bull. int. Ass. med. Mus., 10, 111.

(1936). Atlas of Congenital Cardiac Disease. New York, American Heart Association.

Armand-Delille, M. P. F. (1908). Bull. Soc. Pédiat. Paris, 10, 144.

Beidleman, B. (1945). Amer. J. ment. Defic., 50, 35.

Benda, C. E. (1947). Mongolism and Cretinism. Heinemann, London. p. 177.

Bodian, M., White, L. L. R., Carter, C. O., and Louw, J. H. (1952). Brit. med. J., 1, 77.

Bor, I., and Padovcová-Ledererová, H. (1951). Pediat. Listy, 6, 19.

Cassel (1917). Berl. klin. Wschr., 54, 159.

Castleman, B., and Kibbec, B. U. (1957). New Engl. J. Med., 257, 672.

Comby, J. (1906). Arch. Méd. Enf., 9, 193.

- (1927). Arch. Méd. Enf., 30, 5. 
Down, J. L. H. (1866). Lond. Hosp. Rep., 3, 259.

Doxiades, L., and Portius, W. (1938). Z. menschl. Vererb. Konstitutlehre, 21, 384.

Edelhaus, M. (1932). Pediatria (Napoli), 40, 587.

Ellis, R.W. B. (1956). Disease in Infancy and Childhood. Livingstone, Edinburgh and London. 2nd ed., p. 188.

Engler, M. (1949). Mongolism (Peristatic Amentia). Wright, Bristol, pp. 49-50.

Esen, F. M. (1957). Arch. Pediat., 74, 243.

Evans, P. R. (1950). Brit. Heart J., 12, 258.

Fennell, C. H. (1903). Lancet, 2, 1650 . Ford, C. E., Jones, K. W., Miller, O. J., Mittwoch, U., Penrose, L. S., Ridler, M., and Shapiro, A. (1959). Lancet, 1,

Fraser, J. (1876). J. ment. Sci., 22, 169.

Garrod, A. E. (1894). St. Bart. Hosp. Rep., 30, 53.

- (1898). Trans. clin. Soc. Lond., $31,316$.

(1899). Trans. clin. Soc. Lond., 32, 6.

Ghosh, S. C., and Biswas, M. L. (1955). J. Indian med. Ass., 25, 472.

Gibson, S., and Clifton, W. M. (1938). Amer. J. Dis. Child., 55, 761.

and Lewis, K. C. (1952). Amer. J. Dis. Child., 83, 317.

Goetsch, C. (1938). J. techn. Meth., 18, 117.

Gossage, A. M. (1898). Lancet, 2, 1062.

Granata, G., Bencini, A., and Parenzan, L. (1952). Pediatria (Napoli), 60281.

Gunn, F. D., and Dieckmann, J. M. (1927). Amer. J. Path., 3, 595.

Guthrie (1898). Lancet, 2, 1062.

Hambach, R. (1953). Ann. prediat. (Basel), 181, 27.

(1956). Čas. Lék. čes., 95, 317.

Hill, W. B. (1908). Quart. J. Med., $2,49$.

Hutchison, R. (1913). Lectures on Diseases of Children. Arnold, London. 3rd ed, p. 282.

Ingalls, T. H. (1947). Amer. J. Dis. Child., 73, 279

Ireland, W. W. (1877). Idiocy and Imbecility. Churchill, London.

Jacobs, P. A., Baikie, A. G., Court Brown, W. M., and Strong, J. A. (1959). Lancet, 1, 710.

Kaiser, A., and Schmid, F. (1952). Münch. med. Wschr., 94, 2167.

Keith, A. (1909). Lancet, 2, 433.

Keith, J. D., Rowe, R. D., and Vlad, P. (1958). Heart Disease in Infancy and Childhood. Macmillan Co., New York. Chap. 49.

Kellner (1913). Münch. med. Wschr., 60, 746

Leech, C. B. (1935). J. Pediat., 7, 802.

Lightner, C. M. (1939). J. techn. Meth., 19, 148.

Mall, F. P. (1912). Amer. J. Anat., 13, 249.

Manchanda, S. S., and Guleria, J. S. (1958). Indian. J. Child. Hlth., 7, 101.

Mannheimer, E. (1949). Morbus Caruleus. An analysis of 114 cases of Congenital Heart Disease with Cyanosis. Bibliotheca Cardiologica, Supplementa ad Cardiologa. Basel, Karger. Fasc. 4.

Meeker, L. H. (1935). J. techn. Meth., 14, 72.

Mitchell, A. (1876). J. ment. Sci., 22, 174.

Morgan, D. R., and Sprenkel, V. (1936). J. Techn. Meth., 16, 68.

Muir, J. (1903). Arch. Pediat., 20, 161.

Müller, K. (1955). Z. ärztl. Fortbild., 49, 408.

Neumann, H. (1899). Berl. klin. Wschr., 36, 210.

Orel, H. (1927). Z. Kinderheilk., 44, 449.

Øster, J. (1953). Mongolism. Danish Science Press, Copenhagen. English translation. p. 37.

Potter, E. L. (1952). Pathology of the Fetus and the Newborn Chicago, Year Book Publishers, Inc., p. 225.

Robinson, D. W. (1941). Arch. Path. (Chicago), 32, 117.

Robson, G. M. (1931). Amer. J. Path., 7, 229.

Schleussing, H. (1925). Virchow's Arch. path. Anat., 254, 579.

Sheldon, W. (1955). Diseases of Infancy and Childhood. Churchill, London. 7th ed., p. 645.

Síkl, H. (1951). Pediat. Listy, 6, 15.

Silvy, M. (1934). Mongolisme et Malformations Cardiaques. Thesis, Univ. Paris.

Smith, T. (1896). Brit. med. J., 2, 618.

Spühler, N. (1929). Rev. méd. Suisse rom., 49, 258.

Still, G. F. (1898-1899). King's Coll. Hosp. Rep., 6, 51.

Strauss, L. (1953). Trans. Amer. Coll. Cardiol., 3, 214.

Stuckey, D. (1956). Brit. Heart J., 18, 519.

Sutherland, G. A. (1899). Practitioner, 63, 632.

(1900). Lancet, 1, 23.

Thomson, J. (1898). Scot. med. surg. J., 2, 203.

- (1947). In Oxford Medicine (edited by Christian, H.A.). Oxford University Press, Vol. II, p. 371.

Thursfield, H. (1921). Brit. J. Child. Dis., 18, 18.

Turpin, R., and Gorin, R. (1941). Bull Soc. pédiat. Paris, 38, 273.

von Hofe, F. H. (1922). Arch. Pediat., 39, 737.

Wolf, I. J., and Levinsohn, S. A. (1939). Amer. Heart J., 18, 241.
Wyllie, W. G. (1953). In Diseases of Children (edited by Moncrieff, A. and Evans, P.). Arnold, London. 5th ed., p. 1190. 
APPENDIX

Nature and Distribution of Cardiac Malformations by Age at Death and SeX in 79 Mongols and in 300 OTHER Children with Congenttal Heart Defects

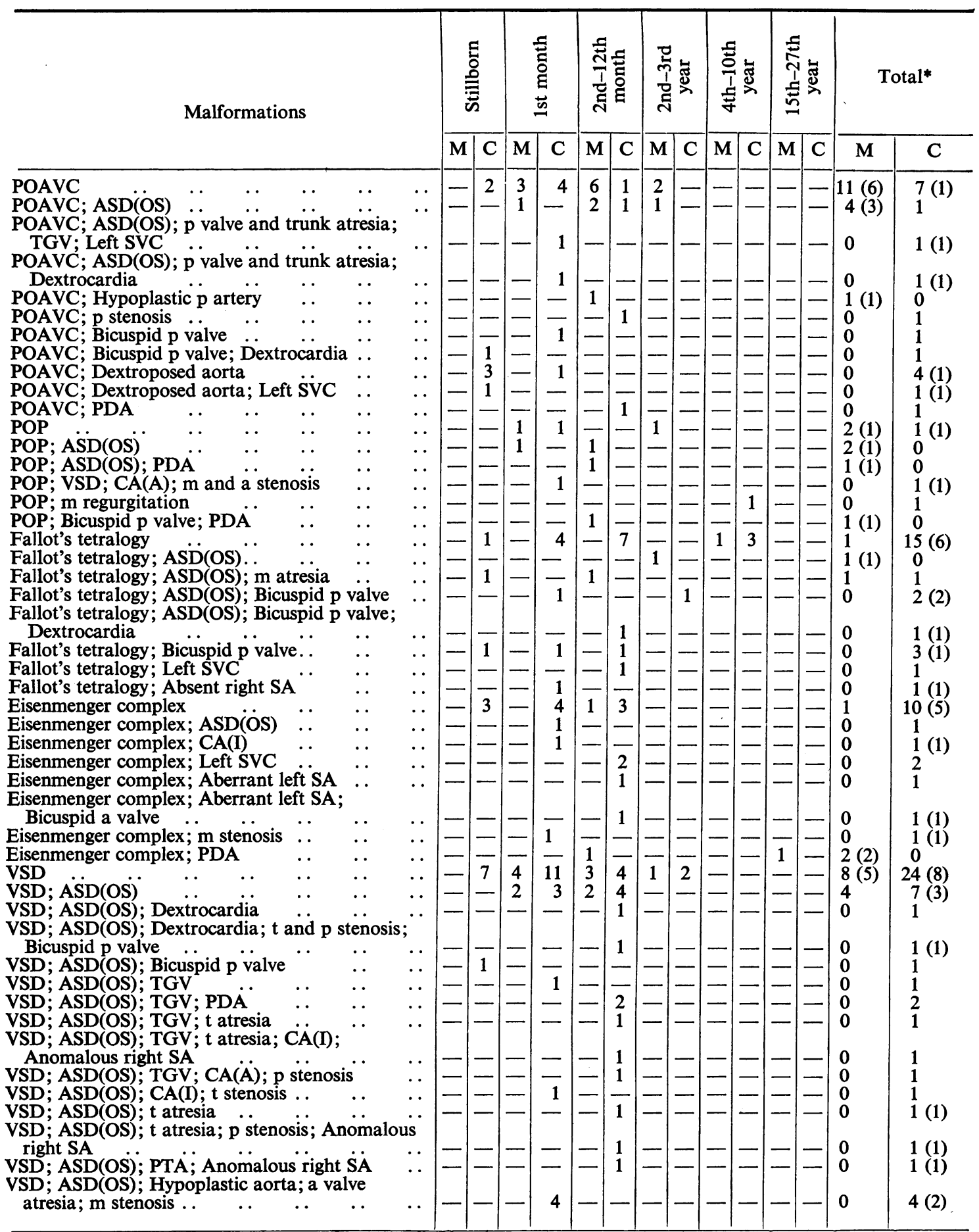




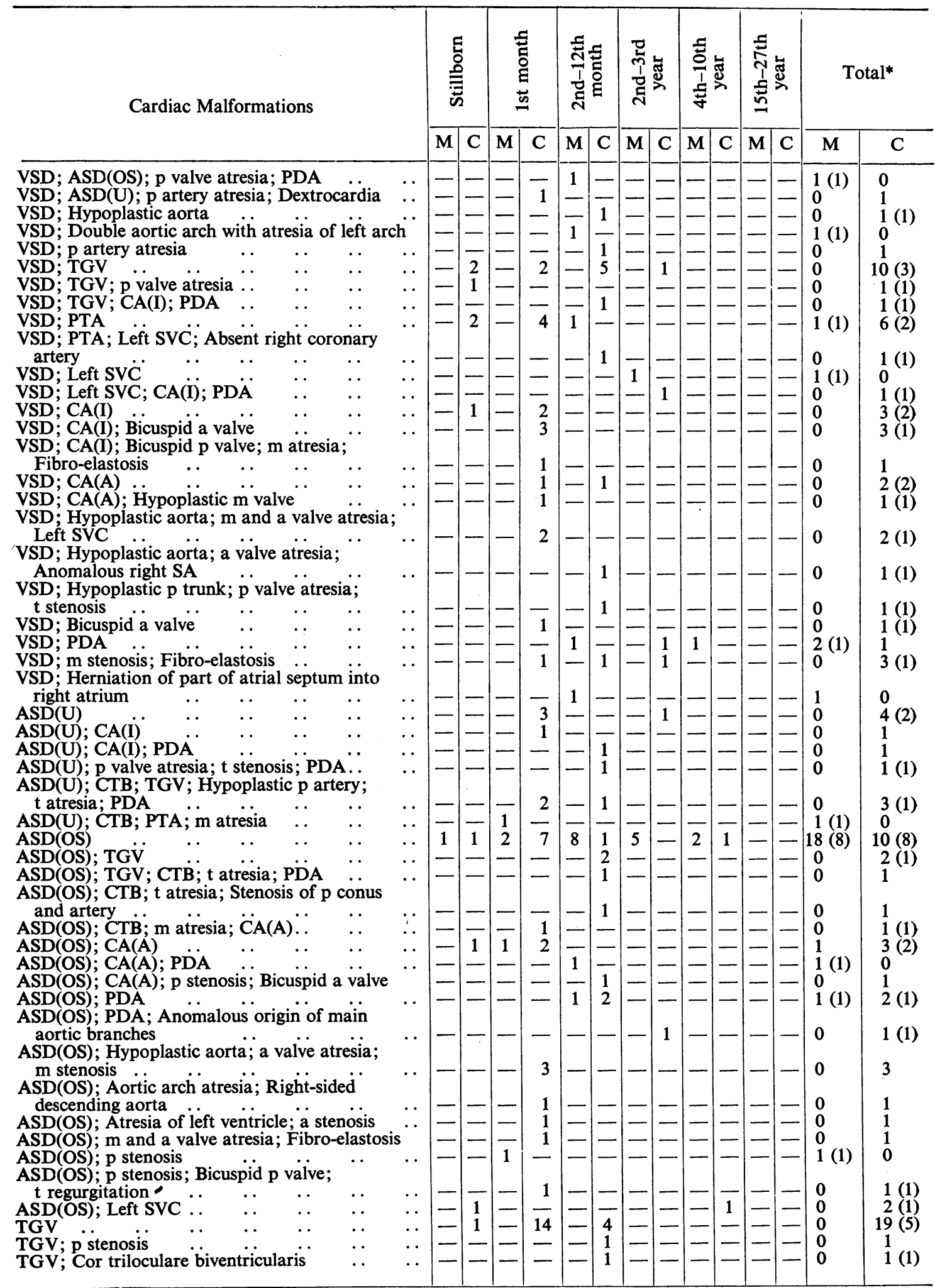




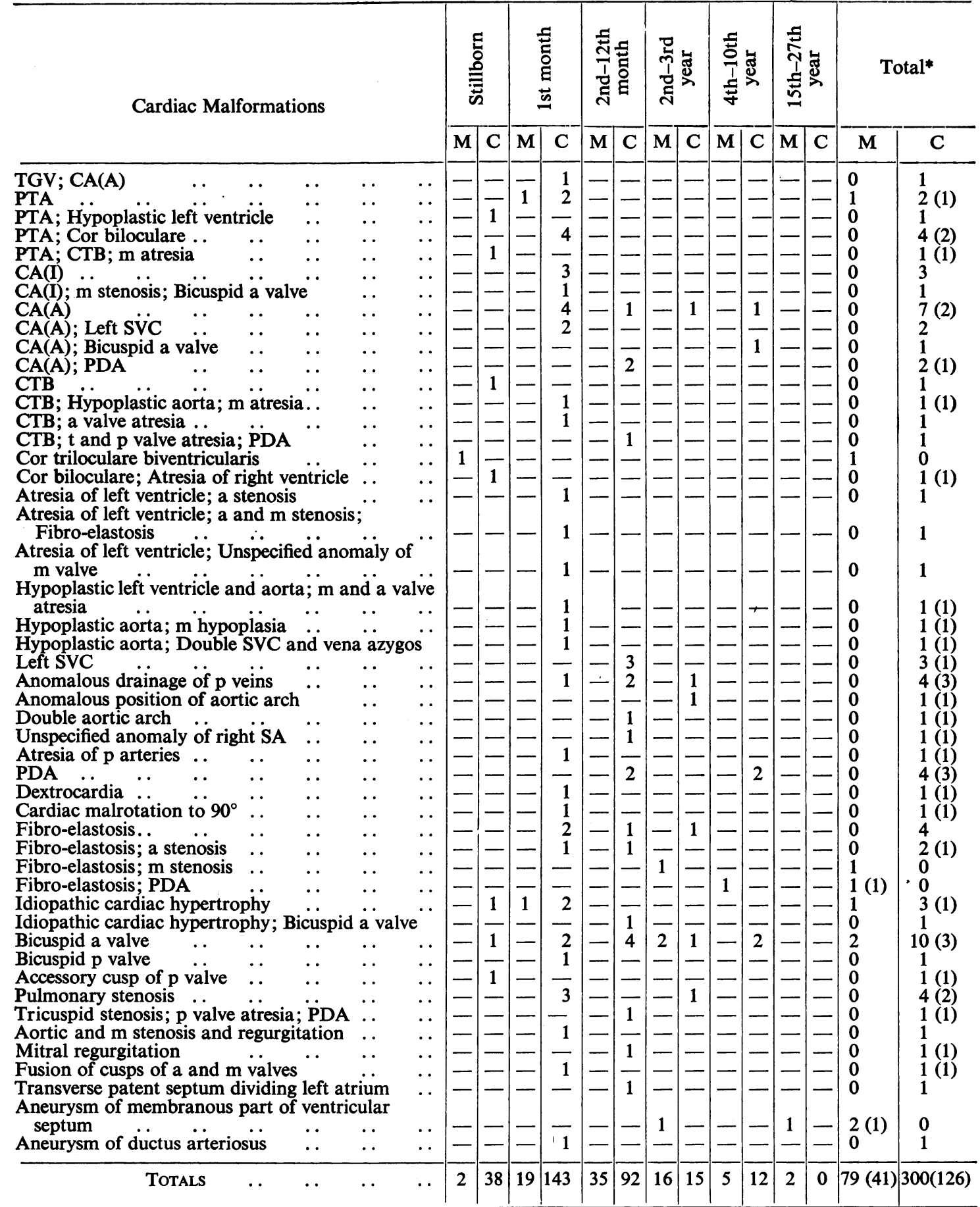

* No. of female cases if any, in brackets

Key: $\mathrm{M}=$ mongols. $\mathrm{C}=$ controls. $\mathrm{a}=$ aortic. $\mathrm{m}=$ mitral. $\mathrm{p}=$ pulmonary. $\mathrm{t}=$ tricuspid. $\mathrm{CTB}=$ cor triloculare biatrialis. POAVC=persistent ostium A-V commune. POP=persistent ostium primum. VSD=ventricular septal defect. $\mathrm{ASD}(\mathrm{OS})=$ atrial septal defect (ostium secundum). $\mathrm{ASD}(\mathrm{U})=$ atrial septal defect (unspecified). TGV= transposition of great vessels. PTA = persistent truncus arteriosus. $\mathrm{CA}(\mathrm{A})=$ coarctation of aorta (adult type). $\mathbf{C A}(\mathrm{I})=$ coarctation of aorta (infantile type). PDA = patent ductus arteriosus. SA $=$ subclavian artery. SVC $=$ superior vena cava. 